\title{
Continuously Increasing Price in an Inventory Cycle: An Optimal Strategy for E-Tailers
}

\author{
Prafulla Joglekar, ${ }^{1}$ Patrick Lee, ${ }^{2}$ and Alireza M. Farahani ${ }^{3}$ \\ ${ }^{1}$ Management Department, La Salle University, 1900 W. Olney Avenue, Philadelphia, \\ PA 19141-1199, USA \\ ${ }^{2}$ IS/OM Department, Fairfield University, 1073 North Benson Road, Fairfield, CT 06824-5154, USA \\ ${ }^{3}$ Computer Science and Information Systems Department, School of Engineering and Technology, \\ National University, 11255 North Torrey Pines Road, La Jolla, CA 92037-0515, USA
}

Correspondence should be addressed to Prafulla Joglekar, joglekar@lasalle.edu

Received 31 May 2007; Accepted 21 April 2008

Recommended by Andreas Soteriou

Operations researchers have always assumed that when a product's unit cost is constant and its demand curve is known and stationary, a retailer of the product would find it optimal to replenish the inventory with a fixed quantity and to sell the product always at a fixed price. We present, with proof, a model that shows that, in such a case, an e-tailer is better off using a continuously increasing price strategy than using a fixed price strategy within each inventory cycle. Sensitivity analysis shows that this strategy is particularly profitable when demand is highly price sensitive and the inventory ordering and carrying costs are high.

Copyright (C) 2008 Prafulla Joglekar et al. This is an open access article distributed under the Creative Commons Attribution License, which permits unrestricted use, distribution, and reproduction in any medium, provided the original work is properly cited.

\section{Introduction}

When a retailer of a product buys the product at a constant unit cost, incurs a fixed cost per order, stores the product at a constant carrying cost per unit of inventory per year, and faces a deterministic and constant demand rate over an infinite horizon, the economic order quantity (EOQ) model tells us that the retailer's optimal strategy is to buy a fixed quantity every time he or she buys. Ignoring inventory related costs, classical price theory tells us that when a product's demand is price sensitive but the demand curve is known and stationary, the retailer's optimal strategy is to charge a single price throughout the year. Whitin [1] was the first one to integrate the concepts of inventory theory with the concepts of price theory to investigate the simultaneous determination of price and order quantity decisions of a retailer. Although he never stated so explicitly, Whitin [1] assumed that when all assumptions of the EOQ model are valid except that demand is price sensitive, with a known and stationary 
demand curve, a retailer's optimal strategy would be, once again, to buy a fixed quantity every time he buys and to sell it at a single price throughout the inventory cycle.

Kunreuther and Richard [2] sought to show that when demand is price elastic, centralized decision-making (using simultaneous determination of optimal price and order quantity) was superior to the common practice of decentralized decision-making whereby the price decisions of a retailer were made by the marketing department and given that price, the order quantity decisions were made by the operations department. Although Kunreuther and Richard [2] were perhaps unaware of Whitin's [1] paper, their model was very similar to Whitin's [1] model. Assuming a known and stationary demand curve along with the remaining conditions of the EOQ model, they asserted: "given constant marginal costs of holding and purchasing the goods, the firm will want to maintain the same price throughout the year" [3, page 173]. Thus, Kunreuther and Richard [2] explicitly stated their assumption that the retailer's selling price would be constant throughout the year. What they did not realize is that, even though marginal holding costs are constant per unit, a firm's holding costs at any particular time within an inventory cycle are a function of inventory on hand, which itself is a function of the time from the beginning of the inventory cycle. As our research shows, in this situation, a constant price throughout the year is not optimal.

Over the five decades since Whitin's [1] work, numerous authors [4-10] have used Whitin's [1] and Kunreuther and Richard's [2] models as foundations to their own models. However, none of these authors have questioned Whitin's [1] and Kunreuther and Richard's [2] assumption that the retailer's optimal strategy would be to sell the product at a single price throughout the inventory cycle. Considering a situation of price sensitive demand, Abad $[10,11]$ found that, in the case of a temporary sale with a forward buying opportunity, a retailer's optimal strategy is to charge two different prices during the last inventory cycle of the quantity bought on sale-a low price at the beginning of the inventory cycle and a higher price starting somewhere in the middle of the cycle. Yet, Abad $[10,11]$ did not consider a similar strategy in every regular inventory cycle of a product with price sensitive demand.

In this paper, we show that, when demand is price-sensitive, Whitin's [1] and Kunreuther and Richard's [2] assumption of a single price throughout an inventory cycle leads to suboptimal profits for the retailer. During an inventory cycle, a retailer's inventory level and carrying costs are a declining function of time. When a retailer faces a price-insensitive demand, his selling price is set arbitrarily, since any optimizing model would push the price to infinity. In other words, in that situation, price is not seen as a decision variable for any mathematical model. Given an arbitrary price (and corresponding demand), the retailer's only strategy is to minimize his inventory ordering and holding costs by using the EOQ model. However, in today's e-commerce environment, when demand is price sensitive, an e-tailer (e.g., Amazon.com) can adopt a continuously increasing price strategy to minimize the impact of the time-dependent inventory carrying costs. An e-tailer can easily quote different prices for a product to an on-line shopper depending on the time at which the shopper is ready to order the product.

The idea underlying our continuously increasing price strategy is to charge a relatively low selling price at the beginning of an inventory cycle when the on-hand inventory is large. The low price would generate high demand. Consequently, the inventory level as well as the marginal inventory carrying costs would decline rapidly. However, as the inventory cycle progresses, and as the on-hand inventory and the marginal carrying costs decline, the e-tailer can charge increasingly higher prices to maximize profit. 
With the widespread use of revenue management or yield management techniques [1216] in the airline, car rental, and hotel industries today, a time-dependent (or dynamic) pricing strategy has become commonly adopted. Revenue management techniques are typically applied in situations of fixed, perishable capacity and a possibility of market segmentation [15]. However, in recent years, retail and other industries have begun to use dynamic pricing policies in view of their inventory considerations. Elmaghraby and Keskinocak [17] present a comprehensive review of the academic literature on dynamic pricing in the presence of inventory considerations. They find that the bulk of academic literature on dynamic pricing is focused on two market environments. The first is an environment where there is no opportunity for inventory replenishment over the selling horizon and demand is independent over time. In the second environment, inventory replenishment is possible, but customers behave myopically and are unconcerned about future price decreases. Our research is not related to either of these two environments.

Elmaghraby and Keskinocak's [17] review suggests that the paper of Rajan et al. [18] may be the only study in the available literature that is relevant to the scope and purpose of our study. Rajan et al. [18] also focus on the price changes that can occur during a seller's inventory cycle. However, they focus on a seller who sells a single perishable product that deteriorates over time and may or may not experience a reduction in its value due to that deterioration. We show that even for a nonperishable product with replenishment possibility, a dynamic pricing strategy makes sense. We present a model that shows that, when the demand curve for a nonperishable product is known and stationary, a retailer is better off using a continuously increasing price strategy within each inventory cycle. Because the continuously increasing price policy we are envisioning is likely to be practical primarily in online retail environments, we say that an e-tailer is better off using a continuously increasing price strategy within each inventory cycle.

The applicability of our model and many other models we have referenced here may be limited by the fact that they all assume deterministic customer behavior and any lack of competitive reactions to one's actions. To the extent that customer behavior is stochastic and competitors do react to a firm's actions, these models may be oversimplifications of reality. On the other hand, without some simplification no theoretical or practical model can be built.

In what follows, first we recapitulate Whitin's [1] and Kunreuther and Richard's [2] fixed price strategy model. In the next section, we present our own model. Then, we provide a mathematical proof that the retailer's profit under the continuously increasing price strategy is higher than the profit under the fixed price strategy. Next, we provide several numerical examples considering a linear demand curve and varied values of relevant parameters. The final section provides the conclusions of our analysis along with some directions for future research.

\section{The fixed price model}

Both papers of Whitin [1] and Kunreuther and Richard [2] consider a situation where all the other assumptions of the EOQ model are valid but demand is price sensitive, with a known and stationary demand curve. Whitin's [1] notation is different from Kunreuther and Richard's [2] notation. There are also some minor differences in the details of the two models. However, the following captures the basics of both the models. Although the model is applicable to any form of the demand function, for simplicity, we use a linear demand function. 
Let the following notations hold, $C=$ retailer's known and constant unit cost of buying the product, $S=$ retailer's known and constant ordering cost per order, $I=$ retailer's carrying costs per dollar of inventory per year, $P_{1}=$ retailer's selling price per unit in this model.

It is assumed that $P_{1}>C, D_{1}=$ retailer's annual demand as a function of the selling price, $P_{1} . D_{1}=a-b P_{1}$, where $a$ and $b$ are nonnegative constants, $a$ representing the theoretical maximum annual demand (at the hypothetical price of $\$ 0$ per unit) and $b$ representing the demand elasticity (i.e., the reduction in annual demand per dollar increase in price).

Note that since $D_{1}$ must be positive for the conceivable range of values of $P_{1}, a>b P_{1}$ for that range of values of $P_{1}$, and since $P_{1}>C$, it follows that $a>b C$. Let $T=$ the duration of retailer's inventory cycle, and $Q=$ retailer's order quantity per order in this model. Then, $Q=D_{1} T_{1}$. Then $Z_{1}=$ retailer's profit per year under this model

$$
\begin{aligned}
Z_{1} & =\left(P_{1}-C\right) D_{1}-I C\left(\frac{D_{1} T}{2}\right)-\frac{S}{T} \\
& =\left(P_{1}-C-\frac{I C T}{2}\right)\left(a-b P_{1}\right)-\frac{S}{T} .
\end{aligned}
$$

Differentiating $Z_{1}$ with respect to $P_{1}$ and $T$, the first-order conditions for the maximization of this function are

$$
\begin{gathered}
P_{1}=\left(\frac{1}{2}\right)\left(\frac{a}{b}+C\right)+\frac{I C T}{4}, \\
T=\left\{\frac{2 S}{I C\left(a-b P_{1}\right)}\right\}^{1 / 2} .
\end{gathered}
$$

From (2.2) and (2.3), we can see that $T$ satisfies the 3rd degree polynomial

$$
T^{3}-2\left[\frac{a-b C}{b I C}\right] T^{2}+\frac{8 S}{I^{2} C^{2} b}=0 .
$$

Assuming $T_{1}$ is a positive root of (2.4), substituting the optimal price from (2.2) and $T_{1}$ from (2.4) in (2.1), we obtain $Z_{1}$, the retailer's optimal profit from this model, as

$$
Z_{1}=\left(\frac{b}{4}\right)\left[\left(\frac{a}{b}\right)-C-\left(\frac{I C T_{1}}{2}\right)\right]^{2}-\frac{S}{T_{1}} .
$$

We have verified that the second-order conditions (not presented here) fulfil the requirements for a local maximum of the annual profit. Thus, by solving for (2.2) and (2.3) simultaneously, one can obtain the optimal values of the price and the inventory cycle time. Unfortunately, to obtain a closed form solution to these equations, one must solve a cubic equation that has three possible roots for the value of $T$. Of course, we would be interested in only the real root(s). Depending on the coefficients of the cubic equation, the closed form solutions may be of real numbers and/or complex numbers. Hence, in our numerical examples, we rely on Excel Solver to obtain the real and optimal solution to this problem. Of course, when there are multiple real solutions to a cubic equation, Excel gives only one of those solutions. In theory, one should use a software such as MathCAD to obtain all of the possible solutions and then determine which one is the global optimal. We did carry out this strategy for 
several numerical examples. In all the cases, what we found was that only one (if any) of the three solutions results in a real and feasible, hence optimal, solution. Therefore, in Excel Solver, we input feasibility conditions such as price must be greater than unit cost, order quantity must be positive, and annual profit must be positive. Excel also needs reasonable starting values of the decision variables. Once care is taken to input these conditions and reasonable starting values, in our experimentation, Excel Solver has never failed to return the best real solution (if any). Hence, we believe that practicing managers would be adequately served by the use of Excel Solver. They need not worry about obtaining all real roots of the cubic equation.

\section{The continuously increasing price model}

We retain all of the assumptions of the foregoing model, except that now we assume that the retailer uses a continuously increasing price strategy within each inventory cycle.

Let us add the following notation: $t=$ time elapsed from the beginning of an inventory cycle, $P_{2}(t)=$ the retailer's selling price at time $t=f+g t$, where $f$ and $g$ are nonnegative decision variables, and $f>C$. $f$ represents the retail price at the beginning of each inventory cycle and $g$ represents the annual rate of increase in the retail price throughout an inventory cycle.

Given that price is a function of time, now the retailer's annual demand rate will also be a function of time. Hence, we should redefine demand as

$$
D_{2}(t)=a-b P_{2}(t)=a-b f-b g t
$$

Also let $X(t)=$ retailer's inventory at time $t, T=$ the duration of retailer's inventory cycle.

Since at the beginning of the inventory cycle, the retailer orders a quantity $Q$ to meet the cycle time demand, then

$$
Q=X(0)=\int_{0}^{T} D_{2}(t) \mathrm{d} t=\int_{0}^{T}(a-b f-b g t) \mathrm{d} t=(a-b f) T-\left(\frac{b g}{2}\right) T^{2},
$$

and at time $t$, the retailer's on-hand inventory is given by

$$
\begin{aligned}
X(t) & =\int_{0}^{T} D_{2}(t) \mathrm{d} t-\int_{0}^{t} D_{2}(t) \mathrm{d} t \\
& =(a-b f) T-\left(\frac{b g}{2}\right) T^{2}-(a-b f) t+\left(\frac{b g}{2}\right) t^{2} .
\end{aligned}
$$

Let $Y=$ retailer's profit per inventory cycle. $Y$ is given by

$$
Y=\int_{0}^{T}\left[P_{2}(t)-C\right] D_{2}(t) \mathrm{d} t-I C \int_{0}^{T} X(t) \mathrm{d} t-S .
$$

When simplified, this yields

$$
Y=(a-b f)\left(f-C-\frac{I C T}{2}\right) T+(a-2 b f+b C) \frac{g T^{2}}{2}+b g(I C-g) \frac{T^{3}}{3}-S .
$$


Thus, the retailer's annual profit under this model, $Z_{2}$, is given by

$$
Z_{2}=\frac{Y}{T}=(a-b f)\left(f-C-\frac{I C T}{2}\right)+(a-2 b f+b C) \frac{g T}{2}+b g(I C-g) \frac{T^{2}}{3}-\frac{S}{T} .
$$

To derive the first-order conditions for the maximization of $Z_{2}$, differentiating $Z_{2}$ with respect to $f$ and equating it to zero, we obtain

$$
f^{*}=\left(\frac{1}{2}\right)\left(\frac{a}{b}+C\right)+\left(\frac{I C}{4}-\frac{g^{*}}{2}\right) T .
$$

Differentiating $Z_{2}$ with respect to $g$ and equating it to zero, we obtain

$$
f^{*}=\left(\frac{1}{2}\right)\left(\frac{a}{b}+C\right)+\left(\frac{I C}{3}-\frac{2 g^{*}}{3}\right) T .
$$

From (3.7) and (3.8), we can see that the optimal values of $g$ and $f$ are given by

$$
\begin{aligned}
& g^{*}=\frac{I C}{2}, \\
& f^{*}=\left(\frac{1}{2}\right)\left(\frac{a}{b}+C\right) .
\end{aligned}
$$

An interesting thing to note here is that the optimal value of the price increase per year, $g^{*}$, is one half of the cost of carrying one unit for one year. In other words, the retailer's optimal selling price at the beginning of the cycle will be $f^{*}$ while his optimal selling price for a unit at the end of the cycle will be $\left(f^{*}+I C T / 2\right)$. This makes intuitive sense. A unit in stock at the beginning of an inventory cycle, if unsold, will be carried (on an average) over one half of the duration of the cycle. Hence, it would cost the retailer ICT $/ 2$ to carry it, whereas a unit in stock at the end of the cycle will not incur any additional carrying cost since it will be simply sold. Hence, the retailer can afford to charge the amount ICT / 2 less for a unit at the beginning of the cycle (and save that carrying cost if the unit sells immediately) compared to the price for a unit at the end of the cycle. In the process, the retailer benefits from the greater demand generated by that lower price in the early part of an inventory cycle.

Differentiating $Z_{2}$ with respect to $T$, equating it to zero, and substituting the optimal values of $f$ and $g$ from (3.9), we see that, in this model, $T$ satisfies the 3 rd-degree polynomial

$$
T^{3}+\left[\frac{3(b C-a)}{2 b I C}\right] T^{2}+\frac{6 S}{b I^{2} C^{2}}=0 .
$$

Given that (3.10) is a cubic equation, we have three possible roots for the value of $T$. Of course, we would be interested in only the real root(s). As we said in the context of the fixed price model, there is no simple closed form solution to obtain the real root(s) of a cubic equation. Hence, in our numerical examples, we rely on Excel Solver to obtain the real and optimal solutions to this problem. As in the case of the fixed price model, we input several feasibility conditions and provide reasonable starting values for the decision variables. We are happy to report that, in our experimentation with this model also, Excel Solver has never failed 
to return the best real solution (if it exists). Hence, we believe that practicing managers would be adequately served by the use of Excel Solver.

We tried to verify whether the second-order conditions of this model (not presented here) fulfil the requirements for a local maximum of the annual profit. Unfortunately, the results are not conclusive. They indicate either a local maximum or an inflection point. Thus, once again, in theory, we will have to first obtain a numerical solution to $T$ and then verify if that solution gives a local maximum for the retailer's profit by perturbing the solution value of $T$ and checking its impact on the profit value. In our numerical experiments with this model, the solution given by Excel Solver was always a local optimum (if it existed) rather than an inflection point.

Note that if $T_{2}$ is a positive solution of (3.10), substituting optimal $f^{*}, g^{*}$, and $T_{2}$ in (3.6), we get $Z_{2}$, the optimal profit from this model, as

$$
Z_{2}=\left(\frac{b}{4}\right)\left[\left(\frac{a}{b}\right)-C\right]^{2}+\left(\frac{b}{4}\right)\left[\left(\frac{a}{b}\right)-C\right] I C T_{2}+\left(\frac{b}{4}\right)\left(\frac{I C T_{2}^{2}}{3}\right)-\left(\frac{S}{T_{2}}\right) .
$$

Now let us prove that $Z_{2}$ of (3.11), the retailer's optimal profit from the continuously increasing price model, is greater than or equal to $Z_{1}$ of (2.5), the retailer's optimal profit from the fixed price model.

\section{Proof of $Z_{2} \geq Z_{1}$}

To simplify (2.4) and (3.10), let us define

$$
\begin{gathered}
u=\frac{2(a-b C)}{b I C}, \\
v=\frac{8 S}{I^{2} C^{2} b} .
\end{gathered}
$$

Note that $v$ is clearly greater than zero. Also, we have noted that for both $D_{1}$ and $D_{2}$ to be positive, we must have $a>b C$. It follows that $u>0$.

Now we can rewrite (2.4) and (3.10) as

$$
\begin{gathered}
T^{3}-u T^{2}+v=0, \\
T^{3}-\frac{3}{4} u T^{2}+\frac{3}{4} v=0 .
\end{gathered}
$$

We are interested in the real positive roots of $\left(2.4^{\prime}\right)$ and $\left(3.6^{\prime}\right)$ since the maximizing cycle time $T$ for the profit functions (2.1) and (3.6) are among these roots, respectively.

The following lemmas present some interesting results on these positive real roots. For convenience, let us designate the left-hand side of $\left(2.4^{\prime}\right)$ as $\phi_{1}$ and the left-hand side of $\left(3.6^{\prime}\right)$ as $\phi_{2}$.

Lemma 4.1. Equation $\left(3.6^{\prime}\right)$ has two distinct positive real roots if and only if $u^{3}>12 v$.

Proof. From the first- and second-order conditions for the maximization of $\phi_{2}$, we see that $\phi_{2}$ has a local maximum at $T=0$ and a local minimum at $T=(u / 2)$. Note that at $T=0$, the polynomial $\phi_{2}(0)=(3 / 4) v>0$. Also, $\lim _{T \rightarrow \infty} \phi_{2}(T)=\infty$. 
Since the only local minimum of $\phi_{2}(T)$ is at $T=u / 2>0$ with value $\phi_{2}(u / 2)=\left(-u^{3} / 16\right)+$ $(3 / 4) v$, we see that $\left(3.6^{\prime}\right)$ can have two distinct positive real roots if and only if $\left(-u^{3} / 16\right)+$ $(3 / 4) v<0$, that is, if and only if $u^{3}>12 v$.

Lemma 4.2. If $u^{3}>12 v$, then (2.4') has two distinct positive real roots.

Proof. The polynomial $\phi_{1}(T)=T^{3}-u T^{2}+v$ behaves similar to $\phi_{2}(T)$ at points $T=0$ and infinity. Also, $\phi_{1}(T)$ has a local minimum only at $T=(2 / 3) u$. The local minimum of $\phi_{1}(T)$ is $\phi_{1}((2 / 3) u)=\left(-4 u^{3} / 27\right)+v$, and with $u^{3}>12 v$, this minimum is negative. Thus, in this case, $\left(2.4^{\prime}\right)$ has two distinct positive real roots.

Observe that the functions $\phi_{1}$ and $\phi_{2}$ provide the same type of information about $Z_{1}$ and $Z_{2}$ as the first derivatives of $Z_{1}$ and $Z_{2}$ do. Figure 1 shows the general forms of $\phi_{1}$ and $\phi_{2}$ as functions of $T$.

As can be seen from Figure 1 , at the smaller roots, $T_{1}$ and $T_{2}$, of $\left(2.4^{\prime}\right)$ and $\left(3.6^{\prime}\right)$, respectively, $\phi_{1}$ and $\phi_{2}$ are declining with an increase in $T$. Thus, at $T_{1}$ and $T_{2}$ we have local maxima of the profit functions $Z_{1}$ and $Z_{2}$, respectively. At the larger roots of $\left(2.4^{\prime}\right)$ and $\left(3.6^{\prime}\right)$, $\phi_{1}$ and $\phi_{2}$ are increasing which indicates local minima of $Z_{1}$ and $Z_{2}$ at those values of $T$. Since our research is focused on the maximization of $Z_{1}$ and $Z_{2}$, in the remainder of this paper, we only consider the smaller positive roots of $\left(2.4^{\prime}\right)$ and $\left(3.6^{\prime}\right)$.

We next state a lemma that gives a lower bound for these roots.

Lemma 4.3. If $u^{3}>12 v$ and $T_{1}$ and $T_{2}$ are the smaller of the two positive roots of $\left(2.4^{\prime}\right)$ and $\left(3.6^{\prime}\right)$, respectively, then $\sqrt{v / u}<T_{1}, T_{2}$.

Proof. Since $u^{3}>12 v$, then $\sqrt{v / u}<(1 / 2) u<(2 / 3) u$. Consider the interval $(\sqrt{v / u},(2 / 3) u)$; note that $\phi_{1}(\sqrt{v / u})>0$ and $\phi_{1}((2 / 3) u)<0$. Since $\phi_{1}(T)$ is continuous on the interval $(\sqrt{v / u},(2 / 3) u)$, we see that the root $T_{1} \in(\sqrt{v / u},(2 / 3) u)$. Therefore, $\sqrt{v / u}<T_{1}$.

We can similarly prove that $\sqrt{v / u}<T_{2}$.

Lemma 4.4. If $u^{3}>12 v$ and $T_{1}$ and $T_{2}$ are the smaller of the two positive roots of $\left(2.4^{\prime}\right)$ and $\left(3.6^{\prime}\right)$, respectively, then $T_{1}<T_{2}$.

Proof. We prove this lemma by contradiction.

Condition $u^{3}>12 v$ insures the existence of two positive roots of $\left(2.4^{\prime}\right)$ and (3.6').

Suppose $T_{2} \leq T_{1}$, then

$$
\begin{aligned}
\phi_{1}\left(T_{2}\right) & =T_{2}^{3}-u T_{2}^{2}+v \\
& =T_{2}^{3}-\frac{3}{4} u T_{2}^{2}-\frac{1}{4} u T_{2}^{2}+\frac{3}{4} v+\frac{1}{4} v \\
& =\left(T_{2}^{3}-\frac{3}{4} u T_{2}^{2}+\frac{3}{4} v\right)-\frac{1}{4} u T_{2}^{2}+\frac{1}{4} v \\
& =\varphi_{2}\left(T_{2}\right)-\frac{1}{4} u T_{2}^{2}+\frac{1}{4} v=-\frac{1}{4} u T_{2}^{2}+\frac{1}{4} v,
\end{aligned}
$$

where $\phi_{2}\left(T_{2}\right)=0$.

Because $T_{1}$ is the smallest positive root of $\phi_{1}(T)$, and $T_{2} \leq T_{1}$, we must have $\phi_{1}\left(T_{2}\right) \geq 0$, which implies that $-(1 / 4) u T_{2}^{2}+(1 / 4) v \geq 0$, but this requires that $T_{2} \leq \sqrt{v / u}$ which contradicts Lemma 4.3. Therefore, $T_{1}<T_{2}$. 


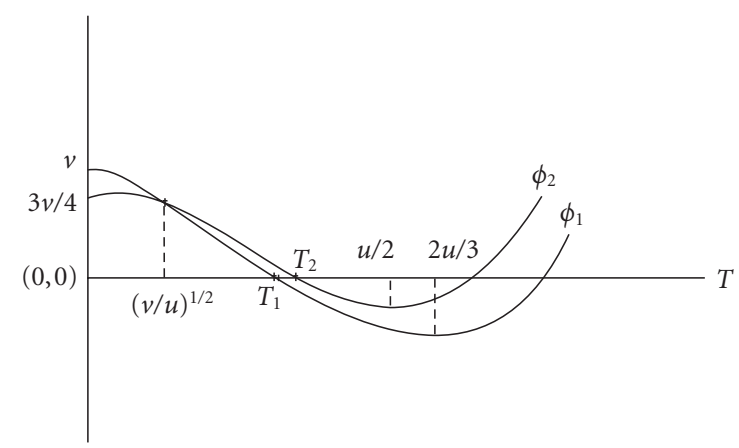

Figure 1: $\phi_{1}$ and $\phi_{2}$ as functions of $T$.

Theorem 4.5. Suppose $a>b C$ and $8(a-b C / b I C)^{3}>96 S / I^{2} C^{2} b$.

Let $T_{1}$ be the smallest positive real root of $\left(2.4^{\prime}\right)$, and let $T_{2}$ be the smallest positive real root of $\left(3.6^{\prime}\right)$, then the maximized profit of (3.11) is larger than the maximized profit of (2.5).

Proof. To show that difference $Z_{2}-Z_{1}$ is positive, we need to show that

$$
Z_{2}-Z_{1}=\frac{b}{4}\left(\frac{a-b C}{b}\right) I C\left[T_{2}-T_{1}\right]+\frac{b}{4} I^{2} C^{2}\left[\frac{T_{2}^{2}}{3}-\frac{T_{1}^{2}}{4}\right]+S\left[\frac{1}{T_{1}}-\frac{1}{T_{2}}\right]>0 .
$$

For that to be true, it suffices to show that $T_{1}<T_{2}$.

Using the substitution $u=2(a-b C / b I C)$, and $v=8 S / I^{2} C^{2} b$ in $\left(2.4^{\prime}\right)$ and $\left(3.6^{\prime}\right)$, we can apply Lemma 4.4 to see that $T_{1}<T_{2}$.

Thus, we have established that the maximized profit under the continuously increasing price strategy is larger than the maximized profit under the fixed price strategy.

Corollary 4.6. Let $P_{1}^{*}$ be the optimal price given by (2.2). For $f^{*}$ and $g^{*}$ given by (3.9), respectively, and the optimal times $T_{1}$ and $T_{2}$ in Theorem 4.5, one has the inequality $f^{*}<P_{1}^{*}<f^{*}+g^{*} T_{2}$.

Proof. From (2.2) and (3.9), we see that $P_{1}^{*}-f^{*}=I C T_{1} / 4>0$. Thus $P_{1}^{*}>f^{*}$.

On the other hand, since $T_{2}>T_{1}$,

$$
f^{*}+g^{*} T_{2}-P_{1}^{*}=\frac{1}{2}\left(\frac{a}{b}+C\right)+\frac{I C}{2} T_{2}-\frac{1}{2}\left(\frac{a}{b}+C\right)-\frac{I C T_{1}}{4}=\frac{I C}{4}\left(2 T_{2}-T_{1}\right)>0 .
$$

Corollary 4.6 implies that the range of optimal prices over the inventory cycle in the continuously increasing price model includes the optimal price for the fixed price model. The numerical example in Table 1 below also confirms the above result.

\section{Numerical example: base case}

Consider a situation where the retailer's cost of a product is $\$ 7$ per unit. The theoretical maximum annual demand is 50,000 units and annual demand declines at the rate of 5000 units for each dollar's increase in the price. The ordering costs are $\$ 400$ per order and the carrying 
Table 1: A numerical example.

\begin{tabular}{|c|c|c|c|c|}
\hline \multicolumn{5}{|c|}{ Assumptions common to both models } \\
\hline \multirow{2}{*}{\multicolumn{5}{|c|}{$\begin{array}{c}C=\$ 7 / \text { unit; } \quad a=50,000 \text { units } / \text { year; } \quad b=5000 \text { units } / \text { year; } \\
S=\$ 400 / \text { order; } \quad I=\$ 40 / \text { dollar } / \text { year }\end{array}$}} \\
\hline & & & & \\
\hline \multicolumn{5}{|c|}{ Optimal decisions and consequences under the two models } \\
\hline & & $\begin{array}{l}\text { Fixed price } \\
\text { model }\end{array}$ & $\begin{array}{l}\text { Continuously } \\
\text { increasing price } \\
\text { model }\end{array}$ & $\begin{array}{l}\text { Percent } \\
\text { difference } \\
\text { between the } \\
\text { two models }\end{array}$ \\
\hline \multirow{3}{*}{$\begin{array}{l}\text { Optimal } \\
\text { decisions }\end{array}$} & Cycle time $(T)$ & 0.2053 years & 0.2093 years & $1.95 \%$ \\
\hline & $\begin{array}{l}\text { Price at the beginning of } \\
\text { the cycle }(f)\end{array}$ & $\$ 8.64 /$ unit & $\$ 8.50 /$ unit & $-1.62 \%$ \\
\hline & $\begin{array}{l}\text { Price increase rate per } \\
\text { year }(g)\end{array}$ & None & $\$ 1.40 /$ unit & NA \\
\hline \multirow{5}{*}{ Consequences } & Order quantity $(Q)$ & 1392 units/order & 1416 units/order & $1.72 \%$ \\
\hline & $\begin{array}{l}\text { Price at the end of the } \\
\text { cycle }(=f+g t)\end{array}$ & $\$ 8.64 /$ unit & $\$ 8.79 /$ unit & $1.74 \%$ \\
\hline & Annual demand & 6790 units/year & 6775 units/year & $-0.22 \%$ \\
\hline & Profit per cycle $[Y(T)]$ & $\$ 1487.96 /$ cycle & $\$ 1524.47 /$ cycle & $2.45 \%$ \\
\hline & Profit per year $(Z)$ & $\$ 7249.24 /$ year & $\$ 7284.32 /$ year & $0.48 \%$ \\
\hline
\end{tabular}

costs are $\$ 0.40$ per dollar of inventory per year. We will refer to this set of assumptions as the base case.

Table 1 summarizes the base case assumptions, the optimal decisions and the consequences under the two models. As can be seen there, in the fixed price model, the optimal retail price is $\$ 8.64$ per unit and the optimal inventory cycle time is 0.2053 years. This means that the retailer would order 1392 units per order and would obtain a per cycle profit of $\$ 1487.96$. The retailer's annual demand is 6790 units and his profit under this strategy is $\$ 7249.24$ per year.

In the continuously increasing price strategy model, the optimal retail price is $\$ 8.50$ per unit at the beginning of the cycle and that price increases at the rate of $\$ 1.40$ per year. The optimal cycle time is 0.2093 years. This means that the retail price at the end of the cycle is $\$ 8.79$ per unit, the retailer would order 1416 units per order, and his per cycle profit under this strategy would be $\$ 1524.47$. The retailer's annual demand would be 6775 units and his annual profit would be $\$ 7284.32$.

In addition to reporting these numbers, Table 1 also presents the percent differences between the two models for each relevant decision and consequence. Observe that, in percent terms, the differences are small. In comparison with the fixed price strategy, the continuously increasing price strategy results in a slightly longer cycle time. At the beginning of an inventory cycle, under the continuously increasing price model, the retail price is smaller than what it is under the fixed price model. However, by the end of the cycle, the retail price under the continuously increasing price model is larger than what it is under the fixed price model. As a result, the annual demand is smaller under the continuously increasing price model. The per cycle profit shows a $2.45 \%$ improvement in the continuously increasing price model compared to the per cycle profit under the fixed price model. However, the annual profit is only $0.48 \%$ greater under the continuously increasing price model. Although this increase in the annual profit is modest, it is clear that, for an e-tailer, the continuously increasing price strategy is more 
Table 2: Sensitivity analysis.

\begin{tabular}{llll}
\hline Changed assumption (s) & \multicolumn{2}{c}{ A comparison of the annual profit under the two models } \\
& Fixed price model & $\begin{array}{l}\text { Percent } \\
\text { difference } \\
\text { increasing price model } \\
\text { between the } \\
\text { two models }\end{array}$ \\
\hline $\begin{array}{l}\text { None (base case) } \\
C=\$ 7.70 / \text { unit }\end{array}$ & $\$ 7249.24 /$ year & $\$ 7284.32 /$ year & $0.48 \%$ \\
$a=55,000$ units/year & $\$ 15,339.34 /$ year & $\$ 3048.31 /$ year & $1.83 \%$ \\
$b=5500$ units/year & $\$ 2568.27 /$ year & $\$ 15,364.48 /$ year & $0.16 \%$ \\
$S=\$ 440 /$ order & $\$ 7059.27 /$ year & $\$ 7098.11 /$ year & $2.16 \%$ \\
$I=\$ 0.44 /$ dollar/year & $\$ 7059.27 /$ year & $\$ 7098.11 /$ year & $0.55 \%$ \\
\hline
\end{tabular}

profitable than the fixed price strategy. Furthermore, in a competitive market, every modest increase in profit is desirable.

Arguably, one may wonder if the magnitude of the profit difference between the two models is worth all the fuss. Similarly, one may also argue that the continuously increasing price strategy model may be costlier to implement because it is more complex and because it would call for additional efforts in communicating the pricing strategy to the consumer. However, in a computerized environment, this model is no more difficult to program than the fixed price model, and for an e-tailer to quote a time-dependent price is no more costly than quoting a fixed price when a customer is shopping at the e-tailer's website.

The specific numerical results we have obtained are a function of the numerical assumptions we have made. Hence, in order to identify the circumstances under which the continuously increasing price strategy would be particularly desirable, we carried out a sensitivity analysis, as described in the following section.

\section{Sensitivity analysis}

Table 2 summarizes the results of an analysis where we increased the value of each one of our parameters, one at a time, by $10 \%$ while maintaining the values of the other parameters constant. In each case, Table 2 shows the consequences of these changes on the retailer's annual profits under the two models and the percentage increase in the annual profit that the retailer obtains by using the continuously increasing price strategy as against using the fixed price strategy. For comparison purposes, the first row of Table 2 repeats the profit results of the two models in the base case.

While other things remaining unchanged from the base case, when the retailer's unit cost for the product goes up by $10 \%$ (from $\$ 7$ per unit to $\$ 7.70$ per unit), a retailer who uses the fixed price strategy would obtain an annual profit of $\$ 2993.58$ while a retailer who uses the continuously increasing price strategy would realize a profit of $\$ 3048.31$. Thus, in this situation, the continuously increasing price strategy affords an increase of $1.83 \%$ over the profit provided by the fixed price strategy. When these results are compared with the base case results, we can conclude that, while other things remaining the same, when a retailer's product cost increases, the continuously increasing price strategy becomes substantially more desirable to use. 
Table 2 also indicates that, while other things remaining unchanged, if the theoretical maximum demand increases by $10 \%$, the advantage of the continuously increasing price strategy reduces substantially to only $0.16 \%$ compared to the profit a retailer can make using the fixed price strategy. On the other hand, when demand elasticity increases by $10 \%$, the continuously increasing price strategy seems to be the most desirable compared to all the cases of sensitivity analysis we have presented. In this case, it provides an annual profit that is $2.16 \%$ higher than the profit provided by the fixed price strategy. Other things remaining unchanged, when the ordering cost increases by $10 \%$, the advantage of the continuously increasing price strategy goes up slightly to $0.55 \%$ compared to its base case advantage of $0.48 \%$. In terms of the retailer's profits from the two strategies, the impact of a $10 \%$ increase in inventory carrying costs is identical to that of a $10 \%$ increase in the ordering costs.

Thus, while other things remaining the same, high price elasticity favors the continuously increasing price strategy the most, followed by high unit cost and then by high ordering and carrying costs. It seems appropriate to conclude that the continuously increasing price strategy is particularly desirable for e-tailers of undifferentiated commodities (high price elasticity), and e-tailers whose suppliers have considerable pricing power (high product cost). It should also be attractive to e-tailers of imported products (high ordering costs), e-tailers who also manufacture the product (high set up costs), e-tailers of perishable products (high carrying costs), and e-tailers of products subject to sudden obsolescence (high carrying costs). Note that Rajan et al. [18] have studied the case of perishable products in greater depth. Our findings are consistent with Rajan et al.'s [18] finding that perishable products that only deteriorate but do not lose any value call for an increasing price within an inventory cycle. However, Rajan et al. [18] also found that if a perishable product loses value (i.e., the product simply could not be sold at its original selling price), then it may be optimal to reduce its price as time increases within an inventory cycle. We have not considered the case of products losing any value. On the other hand, we have shown that even for a nonperishable product, the increasing price strategy is optimal within an inventory cycle.

Of course, our sensitivity analysis focused on changes in one parameter at a time. When several parameters are favorable to the continuously increasing price strategy, the gains offered by this strategy need not remain modest.

\section{Conclusion}

Traditionally, operations researchers (Whitin [1], Kunreuther and Richard [2], and others) have assumed that when a product's demand curve is known and stationary, a retailer of the product would find it optimal to buy a fixed quantity every time he buys and to sell the product at a fixed price throughout the year. We find that this assumption leads to suboptimal pricing policy. Instead, we have shown that, within each inventory cycle, a continuously increasing price strategy is more desirable than the fixed price strategy. Our model resulted in an optimal increase per year of one half of unit holding cost, which made intuitive sense.

A continuously increasing price strategy might have been deemed impractical in the past. However, today's e-tailers can easily adopt this strategy. Elmaghraby and Keskinocak's [17] review of dynamic price models indicates that a number of industries are already using continuously changing pricing strategies.

Our numerical example suggests that often the advantage of a continuously increasing price strategy is only modest. However, sensitivity analysis shows that this strategy is 
particularly desirable when demand is highly price sensitive or when an e-tailer's supplier commands great pricing power. E-tailers facing high inventory ordering and carrying costs will also find this strategy fairly attractive.

While the continuously increasing price strategy may not be practical for a brick-andmortar retailer, such a retailer could use the dual price strategy model developed by Joglekar [3]. Contending that, during any inventory cycle, the retailer's inventory carrying costs are a declining function of time, Joglekar [3] showed that a retailer who sets two different prices at two different points in an inventory cycle obtains a greater profit than a retailer using a single fixed price throughout the cycle. Our numerical analysis of Joglekar's [3] model (not presented here) showed that a continuously increasing price strategy is superior to his model. However, Joglekar's [3] model's gains are only slightly inferior to the model we have presented here. Hence, a brick-and-mortar retailer may be well served by that model.

There are several directions in which this research can be extended. First, we have assumed that the e-tailer obtains the product from a vendor. The model can be easily extended to a situation where the e-tailer is also a manufacturer of the product. We have already cited numerous works that have continued to use the single price assumption. Clearly, each one of those models needs to be revisited in light of our findings here. Finally, a number of recent models considering the coordination pricing and order quantity decisions across a supply chain [19-22] have assumed a fixed price for each participant of the supply chain. These models also need to be updated by considering a continuously increasing price strategy.

\section{Acknowledgment}

The authors wish to express their gratitude to two JAMDS referees for their careful and encouraging comments which has resulted in this substantially improved manuscript.

\section{References}

[1] T. M. Whitin, "Inventory control and price theory," Management Science, vol. 2, no. 1, pp. 61-68, 1955.

[2] H. Kunreuther and J. F. Richard, "Optimal pricing and inventory decisions for non-seasonal items," Econometrica, vol. 39, no. 1, pp. 173-175, 1971.

[3] P. Joglekar, "Optimal price and order quantity strategies for the reseller of a product with price sensitive demand," Proceedings of the Academy of Information and Management Sciences, vol. 7, no. 1, pp. 13-19, 2003.

[4] R. J. Tersine and R. L. Price, "Temporary price discounts and EOQ," Journal of Purchasing and Materials Management, vol. 17, no. 4, pp. 23-27, 1981.

[5] F. J. Arcelus and G. Srinivasan, "Inventory policies under various optimizing criteria and variable markup rates," Management Science, vol. 33, no. 6, pp. 756-762, 1987.

[6] A. Ardalan, "Combined optimal price and optimal inventory replenishment policies when a sale results in increase in demand," Computers and Operations Research, vol. 18, no. 8, pp. 721-730, 1991.

[7] R. Hall, "Price changes and order quantities: impacts of discount rate and storage costs," IIE Transactions, vol. 24, no. 2, pp. 104-110, 1992.

[8] G. E. Martin, "Note on an EOQ model with a temporary sale price," International Journal of Production Economics, vol. 37, no. 2-3, pp. 241-243, 1994.

[9] F. J. Arcelus and G. Srinivasan, "Ordering policies under one time only discount and price sensitive demand," IIE Transactions, vol. 30, no. 11, pp. 1057-1064, 1998.

[10] P. L. Abad, "Optimal price and lot size when the supplier offers a temporary price reduction over an interval," Computers and Operations Research, vol. 30, no. 1, pp. 63-74, 2003.

[11] P. L. Abad, "Optimal policy for a reseller when the supplier offers a temporary reduction in price," Decision Sciences, vol. 28, no. 3, pp. 637-649, 1997. 
[12] Y. Feng and B. Xiao, "Continuous-time yield management model with multiple prices and reversible price changes," Management Science, vol. 46, no. 5, pp. 644-657, 2000.

[13] J. I. McGill and G. J. van Ryzin, "Revenue management: research overview and prospects," Transportation Science, vol. 33, no. 2, pp. 233-256, 1999.

[14] B. C. Smith, J. F. Leimkuhler, and R. M. Darrow, "Yield management at American Airlines," Interfaces, vol. 27, no. 1, pp. 8-31, 1992.

[15] K. T. Talluri and J. G. van Ryzin, The Theory and Practice of Revenue Management, Kluwer Academic Publishers, Dordrecht, The Netherlands, 2000.

[16] L. R. Weatherford and S. E. Bodily, "A taxonomy and research overview of perishable-asset revenue management: yield management, overbooking and pricing," Operations Research, vol. 40, no. 5, pp. 831-844, 1992.

[17] W. Elmaghraby and P. Keskinocak, "Dynamic pricing in the presence of inventory considerations: research overview, current practices, and future directions," Management Science, vol. 49, no. 10, pp. 1287-1309, 2003.

[18] A. Rajan, R. Steinberg, and R. Steinberg, "Dynamic pricing and ordering decisions by a monopolist," Management Science, vol. 38, no. 2, pp. 240-262, 2002.

[19] Z. K. Weng and R. T. Wong, "General models for the supplier's all unit quantity discount policy," Naval Research Logistics, vol. 40, no. 7, pp. 971-991, 1993.

[20] Z. K. Weng, "Channel coordination and quantity discounts," Management Science, vol. 41, no. 9, pp. 1509-1522, 1995.

[21] Z. K. Weng, "Modeling quantity discounts under general price-sensitive demand functions: optimal policies and relationships," European Journal of Operational Research, vol. 86, no. 2, pp. 300-314, 1995.

[22] T. Boyaci and G. Gallego, "Coordinating pricing and inventory replenishment policies for one wholesaler and one or more geographically dispersed retailers," International Journal of Production Economics, vol. 77, no. 2, pp. 95-111, 2002. 


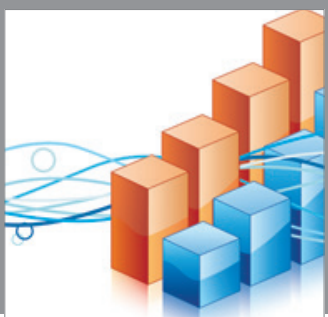

Advances in

Operations Research

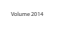

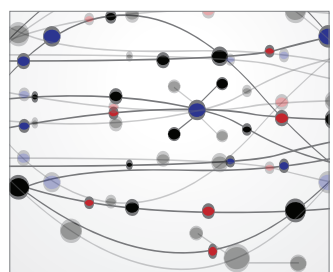

\section{The Scientific} World Journal
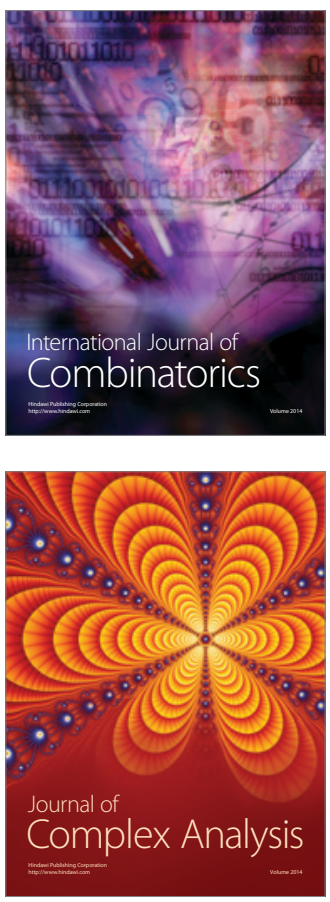

International Journal of

Mathematics and

Mathematical

Sciences
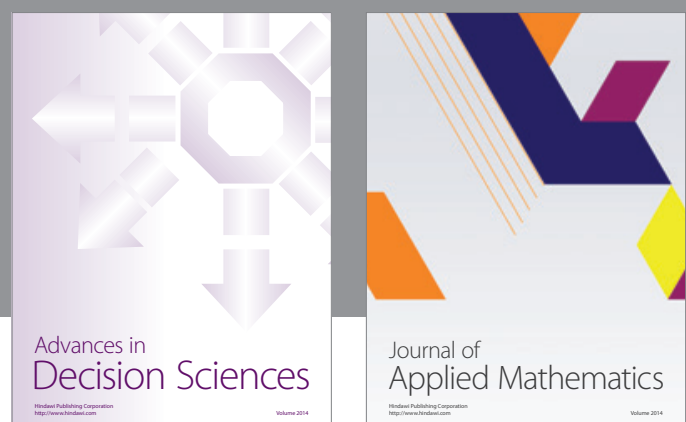

Journal of

Applied Mathematics
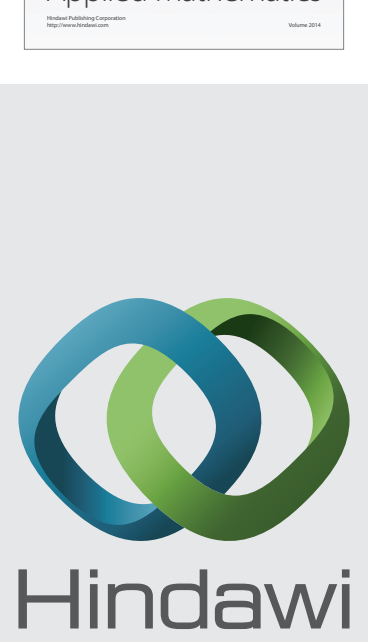

Submit your manuscripts at http://www.hindawi.com
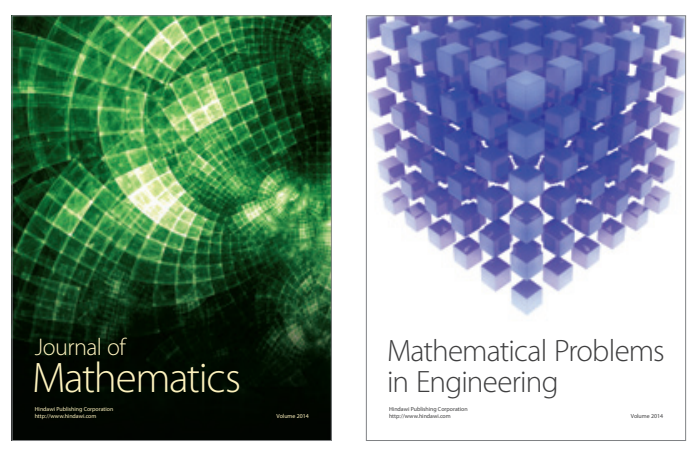

Mathematical Problems in Engineering
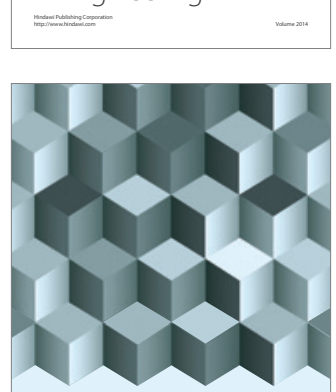

Journal of

Function Spaces
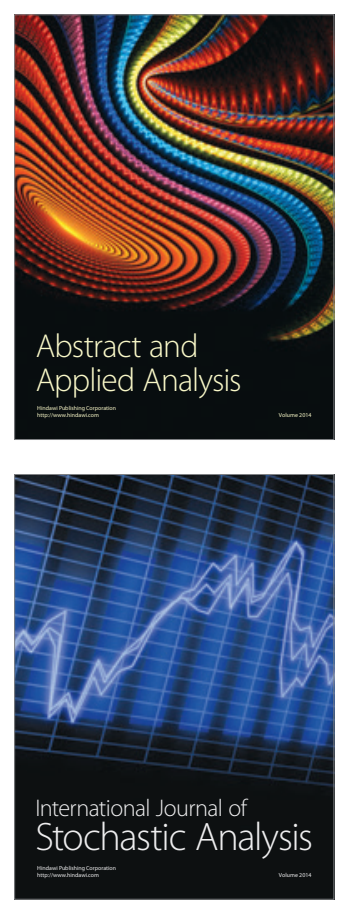

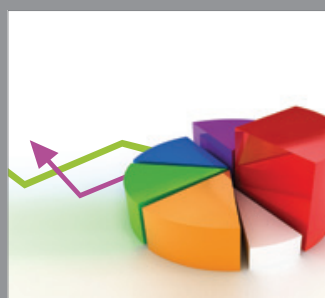

ournal of

Probability and Statistics

Promensencen
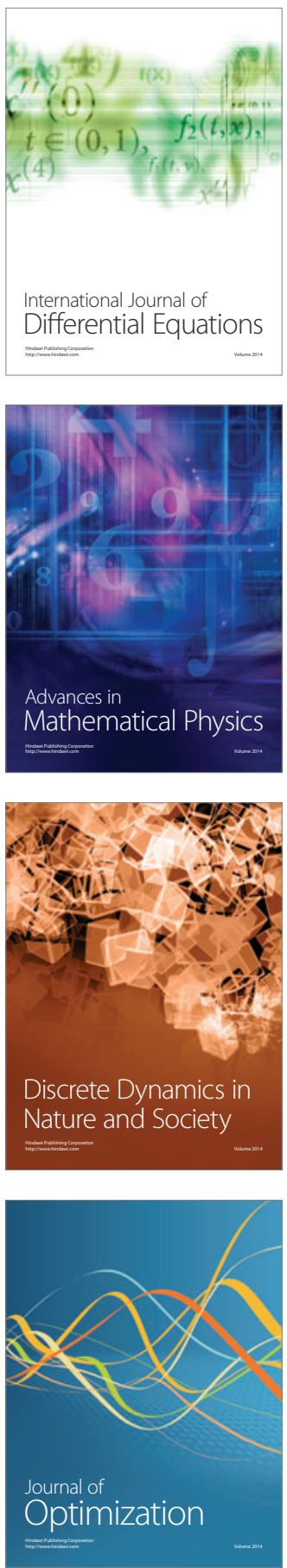